\title{
Post-Concussion Syndrome and Factors Associated With Post- Concussion Syndrome Following Mild Traumatic Brain Injury
}

\author{
Vibol Bo ${ }^{1,2}$, Chatkhane Pearkao ${ }^{3}$ \\ ${ }^{1}$ Master of Nursing Science Program, Faculty of Nursing, Khon Kaen University, Khon Kaen, Thailand, \\ ${ }^{2}$ Odor Meanchey Hospital, Odor Meanchey Provincial Health Department, Ministry of Health, Cambodia, \\ ${ }^{3}$ Associate Professor, Faculty of Nursing, Khon Kaen University, Khon Kaen, Thailand
}

\begin{abstract}
Background: Traumatic Brain Injury (TBI) is a worldwide public health concern especially in developing countries. This study was conducted to describe the prevalence, severity symptoms and determine factors associated with post-concussion syndrome (PCS) following mild traumatic brain injury (MTBI).

Methods: A cross-sectional study was carried out with 218 patients following MTBI after discharged hospital from one week to one year at Odor Meanchey Provincial Hospital (OMCPH) and Anlong Veng Referral Hospital (AVRH). Multiple linear regression was applied to determine factors association.

Results: Of the total 218 patients following MTBI, 79.4\% had symptoms of PCS, with $5.8 \%$ re-hospitalization due to PCS. The most frequently occurring symptoms in PCS following MTBI were from headache $71.7 \%$, being irritable $68.8 \%$, forgetfulness $66.5 \%$, fatigue $62.4 \%$, and taking longer to think $57.2 \%$. Marital status $\beta=-.236, p=.001$, loss of consciousness (LoC) at the time of injury $\beta=-.205, p=.003$, length of hospitalization $\beta=.288, p<0.001$, and readmission $\beta=-.271, p<0.001$ were statistically associated with PCS following MTBI.

Conclusion: Majority of patients had symptoms of PCS. The most frequent symptoms were headache, being irritable, and forgetfulness. Socio-demographic and injury characteristics factors play an essential role in PCS following MTBI.
\end{abstract}

Keywords: Socio-demographics, Injury characteristics, mild traumatic brain injury, post-concussion syndrome

\section{Introduction}

Traumatic Brain Injury is a world public health and socioeconomic problem. Approximately 69 million patients suffered from TBI globally and MTBI accounted for $75 \%-90 \%$ of TBI ${ }^{(1)}$. MTBI is generally influenced by 42 million patients annually around the globe ${ }^{(2)}$. About 5 to $10 \%$ of the population has a history of MTBI in their lives event ${ }^{(3)}$. MTBI refers to an instance of being

\section{Corresponding author:}

Chatkhane Pearkao

Address: Associate Professor, Faculty of Nursing,

Khon Kaen University, Khon Kaen

E-mail: porpea@kku.ac.th injured to the brain which damages to the head caused by an external force ${ }^{(4)}$. External forces probably result from subsequent events including the head being struck by an object, the head striking an object, the head experiencing an acceleration/deceleration movement without direct external trauma to the brain, a foreign body penetrating the head, and forces generated from events including a blast or explosion, or other forces ${ }^{(5)}$. An external physical force probably provokes a change in conditions of consciousness, cognitive or physical functioning impairment, and behavioral or emotional functional interference leading to brain damage ${ }^{(6)}$. The major causes of MTBI are from falls, motor accidents, accidentally hit again something, brain striking on something, a violent attack brain trauma (blast trauma), 
and injuries related with sports ${ }^{(7)}$. According to American Academy of Neurology, MTBI can be categorized into 3 grades based on the following symptoms such as first grade in the confusion without amnesia and LoC in concussion; the second grade is the confusion with amnesia and no $\mathrm{LoC}$ in concussion; the third grade is LoC with a concussion ${ }^{(8)}$.

A complication of MTBI is a significant issue for patients with post-MTBI. Bedaso stated that $41.5 \%$ of MTBI cases experienced PCS with at least 3 symptoms after a head injury such as headache, restlessness, fatigue, and double vision ${ }^{(9)}$. Some previous studies found that $82 \%$ of patients with MTBI after 3-12 months experienced at least one of PCS, $40.3 \%$ decreased life satisfaction, $33 \%$ had functional impairment for 3 months after injury, and only $22.4 \%$ were still not fully functional condition post-injury 1 year ${ }^{(10)}$. Similarly, $84 \%$ of MTBI had post-traumatic complaints and $45 \%$ had emotional distress for 6 months after injury ${ }^{(11)}$, the low function of cognitive and decreased quality of life $(\mathrm{QoL})^{(12)}$, and chronic symptoms ${ }^{(13)}$. There are many symptoms of PCS including headaches, fatigue, vertigo/ dizziness, irritability, emotional lability or irritability, cognitive difficulty (concentration), sleep disturbance and anxiety ${ }^{(14)}$. Many factors associated with PCS following MTBI including retrograde amnesia, difficulty concentrating, disorientation, insomnia, loss of balance, sensitivity to noise, visual disturbance, severity of bodily injury, duration of LoC, duration of PTA, intracranial abnormality, time tested post-injury, possible symptom exaggeration, poor effort, depression, traumatic stress ${ }^{(15)}$, experienced LoC, pre-injury psychological problem and younger age ${ }^{(16)}$.

Cambodia is one of many developing and lowincome countries with a total of approximately 16 million population. According to the 2014 Cambodia Demographic and Health Survey (CDHS), the prevalence of injury from accidents was 72,958 cases and 17 suffered from an injury and 1 died among 1,000 people ${ }^{(17)}$. Describing the prevalence, severity symptoms, and determining factors associated with PCS is extremely crucial for healthcare providers and patients with MTBI. Therefore, this study aimed to describe the prevalence, severity symptoms and factors associated with PCS following MTBI. The results from these findings are extremely crucial to prevent patients from the consequences of post-MTBI as the major causes of patients lose productivity, readmission, disability, and mortality rate for early intervention.

\section{Methods and Materials}

This cross-sectional study was applied to a purposive sampling method. A questionnaire phone call interview was conducted to collect data from July to September 2020. The study was conducted at OMCPH and AVRH, which was under supervised from OMCPHD, Cambodia. All fulfilled patients from the inclusion criteria were purposively chosen proportional to the size of the samples to a total of 218 patients.

\section{Dependent Variables}

The dependent variable was PCS following MTBI. The Revermead Post-Concussion Syndrome Questionnaire (RPQ) was utilized to assess patients who experienced physical, emotional and cognitive symptoms. A 5-point scale was rated on patients 'experience of each of 16 items ( 0 : not experienced at all, 1:no more of a problem, 2: mild problem, 3: moderate problem, and 4:severe problem). A total of 64 scores were summed from 16 questions, representing that higher scores indicate greater severity of PCS.

\section{Independent Variables}

The independent variables (IVs) were age, sex, marital status, education level, employment, cause of MTBI, LoC, alcohol consumption, length of hospitalization, other sustained injuries, duration of PCS occurring, and readmission.

\section{Statistical Analysis}

All analyses were performed using the Statistical Package of Social Science (SPSS). Demographic characteristics (age, sex, marital status, education level, and employment) and Injury Characteristics (cause of MTBI, LoC, alcohol consumption, length of hospitalization, other sustained injuries, duration of PCS occurring, and readmission) were analyzed by using descriptive statistics, which reported frequency and percentage for category variable, mean, standard 
deviation, minimum, and maximum for continuous variable. Multiple linear regression was utilized to predict the association between IVs and PCS following MTBI.

\section{Results}

Among 218 recruited patients aged from 18 to 83 years, the mean age was 35-year-old $(S D=15.292)$, $59.2 \%$ were patients aged from 18 to 35 years old. $72.9 \%$ were males and $60.1 \%$ were married (see table 1 ).

The average year of education was 6.36 years $(S D$ $=4.047), 44 \%$ and $39.4 \%$ completed secondary and primary school respectively. Most patients $81.2 \%$ were employed.

Table 1: The Patient Demographic Data $(n=218)$

\begin{tabular}{|c|c|c|}
\hline Characteristics & Frequency & Percentage (\%) \\
\hline Age (year) Range $=18-83$ unit & $\bar{X}_{=35}$ & $\mathrm{SD}=15.292$ \\
\hline $18-35$ & 129 & 59.2 \\
\hline $36-55$ & 61 & 28.0 \\
\hline$\geq 56$ & 28 & 12.8 \\
\hline Sex & & \\
\hline Female & 59 & 27.1 \\
\hline Male & 159 & 72.9 \\
\hline \multicolumn{3}{|l|}{ Marital status } \\
\hline Married & 131 & 60.1 \\
\hline Single & 87 & 39.9 \\
\hline Education level Range $=0-18$ unit & $\bar{X}_{=6.36}$ & $\mathrm{SD}=4.047$ \\
\hline No formal education & 23 & 10.6 \\
\hline Primary education (1-6 years) & 86 & 39.4 \\
\hline Secondary education ( $7-12$ years) & 96 & 44.0 \\
\hline Tertiary education (13 years or higher) & 13 & 6.0 \\
\hline \multicolumn{3}{|l|}{ Employment } \\
\hline Unemployed & 41 & 18.8 \\
\hline Employed & 177 & 81.2 \\
\hline
\end{tabular}

$\bar{X}=$ Mean, $S D=$ standard deviation 
Motor vehicle collision (MVC) accounted for $70.6 \%$, followed by $29.4 \%$ from Non-Motor vehicle collision (non-MVC). $69.7 \%$ were LoC during the time of injury, and more than one third $39.4 \%$ consumed alcohol at the time of injury.

The mean days of the patient's hospitalization were $3.41(S D=2.106)$.
More than half (54.6\%) had other sustained injuries at the time of injury.

79.4\% had PCS happened after MTBI and 90.8\% had 1-24 weeks of PCS happened after MTBI. The majority of the participants $94.2 \%$ did not readmit to the emergency department (ED) (table 2).

Table 2 Participant's injury characteristic $(n=218)$

\begin{tabular}{|c|c|c|}
\hline Characteristic & Frequency & Percentage(\%) \\
\hline \multicolumn{3}{|l|}{ Cause of MTBI } \\
\hline Motor vehicle collision & 154 & 70.6 \\
\hline Non-Motor vehicle collision & 64 & 29.4 \\
\hline \multicolumn{3}{|l|}{ LoC at the time of injury } \\
\hline Yes & 152 & 69.7 \\
\hline No & 66 & 30.3 \\
\hline \multicolumn{3}{|l|}{ Alcohol Consumption at the time of injury } \\
\hline Yes & 86 & 39.4 \\
\hline No & 132 & 60.6 \\
\hline LoH Range $=1-12$ days & $\bar{X}_{=3.41}$ & $\mathrm{SD}=2.106$ \\
\hline Mode $=2$ & $\mathrm{Mdn}=3.00$ & \\
\hline \multicolumn{3}{|l|}{ Other sustained injuries at the time of injury } \\
\hline Yes & 119 & 54.6 \\
\hline No & 99 & 45.4 \\
\hline \multicolumn{3}{|l|}{ The signs and symptoms happen after MTBI } \\
\hline Yes & 173 & 79.4 \\
\hline No & 45 & 20.6 \\
\hline The duration of signs and symptoms happened after MTBI & $\mathrm{n}=173$ & \\
\hline $1-24$ weeks & 157 & 90.8 \\
\hline $25-48$ weeks & 16 & 9.2 \\
\hline The readmission/revisit to the ED & $\mathrm{n}=173$ & \\
\hline Yes & 10 & 5.8 \\
\hline No & 163 & 94.2 \\
\hline
\end{tabular}

Mdn = median, $\mathrm{sd}=$ standard deviation 
The finding displayed the mean scores of PCS ranged from 1-42 were $14.66(\mathrm{SD}=9.739)$. The most frequently occurring PCS following MTBI were from headache $(71.7 \%)$, being irritable $(68.8 \%)$, forgetfulness (66.5\%), fatigue (62.4\%), and taking longer to think (57.2\%). The least five occurring symptoms were feeling depressed (46.2\%), sleep disturbance (43.4\%), noise sensitivity (38.7\%), double vision (29.5\%), and nausea or vomiting $(22.5 \%)$ (see table 3 ).

Headache $\bar{X}=1.34(S D=1.002)$ and being irritable $\bar{X}=1.31 \quad(S D=1.015)$ are the most severe symptoms while nausea or vomiting $\bar{X}=.32(S D=.636)$ and double vision $\bar{X}=.50(S D=.826)$ are the least severe symptoms compared to other symptoms of PCS.

Table 3: Post-Concussion Syndrome $(n=173)$

\begin{tabular}{|c|c|c|}
\hline Symptoms & $\begin{array}{c}\text { n }(\%) \text { Frequency of } \\
\text { symptoms }\end{array}$ & 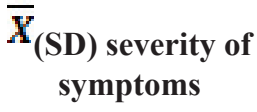 \\
\hline \multicolumn{3}{|l|}{ Range 1-42-unit, $\operatorname{Min}=1, \operatorname{Max}=42$} \\
\hline Headaches & $124(71.7)$ & $1.34(1.002)$ \\
\hline Being irritable & $119(68.8)$ & $1.31(1.015)$ \\
\hline Forgetfulness & $115(66.5)$ & $1.27(1.017)$ \\
\hline Fatigue & $108(62.4)$ & $1.11(.979)$ \\
\hline Taking longer to think & $99(57.2)$ & $1.06(.998)$ \\
\hline Feeling frustrated or impatient & $97(56.1)$ & $.98(.979)$ \\
\hline Feelings of dizziness & $97(56.1)$ & $1.00(1.006)$ \\
\hline Blurred vision & $91(52.6)$ & $.99(1.043)$ \\
\hline Light sensitivity & $86(49.7)$ & $.90(.998)$ \\
\hline Poor concentration & $81(46.8)$ & $.83(.967)$ \\
\hline Feeling depressed or tearful & $80(46.2)$ & $.82(998)$ \\
\hline Restlessness & $80(46.2)$ & $.80(.950)$ \\
\hline Sleep disturbance & $75(43.4)$ & $.79(1.001)$ \\
\hline Noise sensitivity & $67(38.7)$ & $.65(.901)$ \\
\hline Double vision & $51(29.5)$ & $.50(.826)$ \\
\hline Nausea and/or vomiting & $39(22.5)$ & $.32(.636)$ \\
\hline Total & $173(100)$ & $14.66(9.739)$ \\
\hline
\end{tabular}

Simple linear regression analysis on factors associated with PCS following MTBI 
Employment $(p=.368)$, alcohol consumption at the time of injury $(p=.329)$, another sustained injury $(p=.07)$, and duration of PCS occurring ( $p=.396)$ were not significantly associated with PCS following MTBI (table 4).

Age was statistically significantly associated with PCS following MTBI ( $p=.003)$. PCS increased by 0.224 with every increase in age. Age explained $50 \%$ of the variance in PCS.

Length of hospitalization is statistically associated with PCS $(p=.000)$. PCS increased by 0.282 with every increase in the length of hospitalization, which explained $8 \%$ of the variance in PCS.

Sex $(p=.012)$., marital status $(p=.00)$, an education level $(p=.003)$, causes of MTBI $(p=.011), \mathrm{LoC}$ at the time of injury ( $p=.048)$, and readmission ( $p=.001)$ were predicted to be statistically significantly associated with PCS but with every decreased score on each factor.

PCS decreased by .191 on sex, .273 on marital status, .223 on education, .192 on causes of MTBI, .150 on LoC at the time of injury and .246 on readmission.

Table 4: Factors associated with PCS following MTBI on simple linear regression analysis $(\mathrm{n}=173)$

\begin{tabular}{|c|c|c|c|c|c|}
\hline Variable & Constant & $\mathbf{B}$ & $\mathbf{R 2}$ & $\mathbf{F}$ & $\mathbf{p}$ \\
\hline Age & 9.627 & 0.224 & 0.50 & 8.991 & .003 \\
\hline Sex & 21.68 & -.191 & 0.37 & 6.5 & .012 \\
\hline Marital status & 22.207 & -.273 & .075 & 13.784 & .00 \\
\hline Education level & 18.12 & -.223 & 0.05 & 8.94 & .003 \\
\hline Employment & 11.71 & .069 & .005 & .814 & .368 \\
\hline Cause of MTBI & 17.549 & -.192 & .037 & 6.548 & .011 \\
\hline LoC at the time of injury & 18.86 & -.150 & .023 & 3.96 & .048 \\
\hline Alcohol consumption at the time injury & 12.21 & .075 & .006 & .958 & .329 \\
\hline Length of hospitalization & 10.14 & .282 & .08 & 14.77 & .000 \\
\hline Other sustained injury & 18.54 & -.138 & .019 & 3.32 & .07 \\
\hline Duration of PCS occurs & 14.866 & -.065 & .004 & .726 & .396 \\
\hline Readmission & 34.52 & -.246 & .06 & 10.99 & .001 \\
\hline
\end{tabular}

$P<.05=$ Significant 
Multiple linear regression analysis on factors associated with PCS following MTBI

Marital status, LoC at the time of injury, length of hospitalization, and readmission are significant predictors of PCS with $\left(\mathrm{R}^{2}=.243, \mathrm{~F}(4,168)=13.492\right.$, $\mathrm{p}$ value $=<.001)$.
The results revealed that marital status $(\beta=$ $.236, p=.001)$, LoC at the time of injury $(\beta=-.205$, $p=.003)$, length of hospitalization $(\beta=.288, p<.001)$, and readmission $(\beta=-.271, p=<.001)$ were statistically associated with PCS following MTBI.

Table 5: Factors associated with PCS following MTBI on multiple linear regression analysis $(\mathrm{n}=173)$

\begin{tabular}{|c|c|c|c|c|c|}
\hline \multirow{2}{*}{ Variable } & \multirow{2}{*}{$\mathbf{N}$} & $\mathbf{B}$ & $\mathbf{p}$ & \multicolumn{2}{|c|}{$\mathbf{9 5 \%}$ CI } \\
\cline { 4 - 6 } & & & & Lower & Upper \\
\hline Constant & 44.149 & & $<.001$ & 31.515 & 56.783 \\
\hline Marital status & -4.715 & -.236 & .001 & -7.378 & -2.051 \\
\hline LoC at the time of injury & -4.534 & -.205 & .003 & -7.527 & -1.542 \\
\hline Length of hospitalization & 1.313 & .288 & $<.001$ & .709 & 1.917 \\
\hline Readmission & -11.269 & -.271 & $<.001$ & -16.918 & -5.620 \\
\hline
\end{tabular}

$P<.05=$ Significant, $\mathrm{R}=.496, \mathrm{R}^{2}=.243, \mathrm{R}^{2}$ Adjust $=.224, F(4,168)=13.492$

\section{Discussion and Recommendation}

\section{Discussion}

The results of prevalence, severity symptoms, and factors associated with PCS following MTBI represent several aspects of the respondents with MTBI after a hospital discharged.

This current study showed that headache and being irritable symptoms are the most common dangerous symptoms that patients need to be cautious because it has been the main leading causes of patients into the severity following MTBI. This study is consistent with a study conducted in Hawassa city Ethiopia ${ }^{(9)}$. The most frequently occurring symptoms of PCS following MTBI were headache, being irritable, and forgetfulness. This study demonstrated that headache, dizziness, and fatigue accounted for $56.88 \%, 44.5 \%$, and $49.54 \%$, respectively. However, a study demonstrated that up to $84 \%$ of 910 participants reported one or more post- traumatic complaints $(\bar{X}=5.8, S D=4.6)$, which headache accounted for $51 \%$, dizziness $55 \%$, and fatigue $56 \%$ at 2 weeks following MTBI ${ }^{(11)}$. The difference could be the variation in study setting, health care system, and socioeconomic conditions among study respondents.

A study conducted in New Zealand (NZ) stated the top five symptoms of PCS frequently happened at one year following MTBI were headache, fatigue, forgetfulness, poor concentration, and taking longer to think $^{(12)}$. Similarly, this study demonstrated the top five frequently occurring symptoms of PCS less than one year were headache, being irritable, forgetfulness, fatigue, and taking longer to think. It could be considered that PCS symptoms are universal and not unique to TBI and can happen as a result of other medical status or acute illness.

Socio-demographic characteristic such as age and sex were not significantly associated with PCS following MTBI. This present study is in line with other previous 
studies conducted in Ethiopia and America ${ }^{(9,15)}$. This finding indicated that there was no effect on PCS symptoms of some demographic data from the subjects.

Marital status had a statistically significant association with PCS. This is probably because those who get married have the high responsibilities for supporting family and taking good care of their children which make them have less time to take rest postinjury. This present study is consistent with studies in Morocco $^{(18)}$.

Educational level and the cause of MTBI found no significant association with PCS. The results stated that there was no difference among education level and the cause of MTBI of the participants. This is probably participants received the same level of health care services following MTBI. This current study is in line with a study conducted in America ${ }^{(15)}$.

Employment, alcohol consumption, and duration of PCS occurring were not significantly associated with PCS. The differences may be these variables have no impact on PCS. A study in Norway revealed that there was a negative association between alcohol use and PCS following MTBI ${ }^{(19)}$. This study is consistent with studies conducted in Sweden ${ }^{(20)}$.

LoC at the time of injury was significantly predicted with PCS. This means that those who have LoC at the time of injury have the severity of the axonal injury and severe injury than those who no LoC even though they have MTBI. Consistent with a study conducted in America ${ }^{(16)}$.

The participants who stayed longer in the hospital had higher scores than those who stay shorter in the hospital. Patients who stayed longer in the hospital could be at higher risks with PCS because might be they had other sustained injuries at the time of injury compared to those who had a single MTBI. However, the study by Voomolen $^{(21)}$ found no significant association between a number of days of patients being hospitalized and PCS.

Other sustained injuries at the time of injury were not significantly predicted with PCS. The results in this study demonstrated that other sustained injuries at the time of injury could not influence the nerve system, which is closely linked to the brain, therefore, it negatively impacted the occurring of PCS. This is in contrast with a study in Finland ${ }^{(22)}$.

Readmission had a significant prediction with PCS. The findings of the present study indicated that those who were not readmitted to the hospital, PCS scores decreased $.271(\mathrm{p}=.001)$ which was supported by a study conducted in Southeastern America ${ }^{(23)}$.

\section{Conclusion}

Majority of patients had occurring PCS following MTBI, with roughly $5.8 \%$ being revisited in the hospital. Headache and being irritable are the most severe symptoms while nausea or vomiting and double vision are the least severe symptoms. Marital status, LoC at the time of injury, length of hospitalization, and readmission are statistically associated with PCS following MTBI among patients admitted at a surgical unit in $\mathrm{OMCPH}$ and AVRH.

\section{Recommendations}

The following recommendations were highly considered.

National level:

Clinical education and self-care counselling by providing booklets, videos, or applications for MTBI patients, family members, and caregivers should be offered by health care providers to enhance other diseases and PCS-related knowledge.

\section{Local level:}

Family members, caregivers especially MTBI patients should be encouraged to enrol in health education for the prevention of PCS following MTBI.

\section{Future study:}

Longitudinal studies on PCS following MTBI require to be conducted with head trauma and follow up with MTBI patients and address how people benefit from the intervention program and reduce the patient's readmission rate. 
Ethical Considerations: This research was conducted after getting approval from Khon Kaen University Ethics Committee in Human Research $\left(\mathrm{N}_{\mathrm{o}}\right.$. HE632156) and National Ethics Committee for Health Research $\left(\mathrm{N}_{\mathrm{o}}\right.$. 122 NECHR), MoH of Cambodia for protecting the rights of the participants.

Acknowledgement: The authors would like to express sincere appreciation and gratitude to the OMCPHD which supervised OMCPH and AVRH for this study.

Conflict of Interest: No conflicts of interest were disclosed.

Source of Funding: Thailand International Cooperation Agency (TICA) and Training Center for Enhancing Quality of life of Working-Aged People, Thailand.

\section{References}

1. Scholten AC, Haagsma JA, Panneman MJM, Beeck EF van, Polinder S. Traumatic Brain Injury in the Netherlands: Incidence, Costs and DisabilityAdjusted Life Years. PLOS ONE. 2014 Oct 24;9(10):e110905.

2. Gardner RC, Yaffe K. Epidemiology of mild traumatic brain injury and neurodegenerative disease. Molecular and Cellular Neuroscience. 2015;66:75-80.

3. Conder RL, Conder AA. Sports-Related Concussions. North Carolina Medical Journal. 2015 Apr 1;76(2):89-95.

4. Bodin D, Yeates KO, Klamar K. Definition and Classification of Concussion. In: Apps JN, Walter KD, editors. Pediatric and Adolescent Concussion [Internet]. New York, NY: Springer New York; 2012 [cited 2019 Dec 9]. p. 9-19. Available from: http://link.springer.com/10.1007/978-0-38789545-1_2

5. Department of Veterans Affairs Department of Defense. (2016). VA/DoD CLINICAL PRACTICE GUIDELINE FOR THE MANAGEMENT OF CONCUSSION-MILD TRAUMATIC BRAIN INJURY (Rev. ed.).

6. Schutt LM. The effect of functional impairment severity on impaired self awareness, quality of life, and depression in individuals post traumatic brain injury [PhD Thesis]. California School of Professional Psychology, San Diego; 1999.

7. Faul M, Wald MM, Xu L, Coronado VG. Traumatic brain injury in the United States; emergency department visits, hospitalizations, and deaths, 2002-2006. 2010;

8. Heilbronner RL, Bush SS, Ravdin LD, Barth JT, Iverson GL, Ruff RM, et al. Neuropsychological consequences of boxing and recommendations to improve safety: a National Academy of Neuropsychology education paper. Archives of Clinical Neuropsychology. 2009;24(1):11-19.

9. Bedaso A, Geja E, Ayalew M, Oltaye Z, Duko B. Post-concussion syndrome among patients experiencing head injury attending emergency department of Hawassa University Comprehensive specialized hospital, Hawassa, southern Ethiopia. J Headache Pain. 2018 Nov 21;19(1):112.

10. McMahon PJ, Hricik A, Yue JK, Puccio AM, Inoue $\mathrm{T}$, Lingsma $\mathrm{HF}$, et al. Symptomatology and Functional Outcome in Mild Traumatic Brain Injury: Results from the Prospective TRACK-TBI Study. Journal of Neurotrauma. 2014 Jan;31(1):2633.

11. van der Naalt J, Timmerman ME, de Koning ME, van der Horn HJ, Scheenen ME, Jacobs B, et al. Early predictors of outcome after mild traumatic brain injury (UPFRONT): an observational cohort study. The Lancet Neurology. 2017 Jul;16(7):53240.

12. Theadom A, Parag V, Dowell $\mathrm{T}$, McPherson K, Starkey N, Barker-Collo S, et al. Persistent problems 1 year after mild traumatic brain injury: a longitudinal population study in New Zealand. Br J Gen Pract. 2016 Jan;66(642):e16-23.

13. Barker-Collo S, Theadom A, Jones K, Starkey N, Kahan M, Feigin V. Depression and anxiety across the first 4 years after mild traumatic brain injury: findings from a community-based study. Brain Injury. 2018 Dec 6;32(13-14):1651-8.

14. Broshek DK, De Marco AP, Freeman JR. A review of post-concussion syndrome and psychological factors associated with concussion. Brain injury. 2015;29(2):228-237.

15. Lange RT, Brickell T, French LM, Ivins B, Bhagwat A, Pancholi S, et al. Risk Factors for Postconcussion Symptom Reporting after Traumatic Brain Injury in U.S. Military Service Members. Journal of 
Neurotrauma. 2012 Nov 5;30(4):237-46.

16. Ponsford J, Nguyen S, Downing M, Bosch M, McKenzie J, Turner S, et al. Factors associated with persistent post-concussion symptoms following mild traumatic brain injury in adults. J Rehabil Med. 2019;51(1):32-9.

17. Demographic N. Health Survey. 2013. Abuja, Nigeria, and Rockville, Maryland, USA: NPC and ICF International. National Population Commission (NPC)[Nigeria] and ICF International. 2014;12754.

18. Fourtassi M, Hajjioui A, Ouahabi AE, Benmassaoud H, Hajjaj-Hassouni N, Khamlichi AE. Long term outcome following mild traumatic brain injury in Moroccan patients. Clinical Neurology and Neurosurgery. 2011 Nov 1;113(9):716-20.

19. Røe C, Sveen U, Alvsåker K, Bautz-Holter E. Postconcussion symptoms after mild traumatic brain injury: influence of demographic factors and injury severity in a 1-year cohort study. Disability and Rehabilitation. 2009 Jan;31(15):1235-43.

20. Oldenburg C, Lundin A, Edman G, Deboussard
$\mathrm{CN}$, Bartfai A. Emotional reserve and prolonged post-concussive symptoms and disability: a Swedish prospective 1-year mild traumatic brain injury cohort study. BMJ Open [Internet]. 2018 Jul 1 [cited 2019 Dec 13];8(7). Available from: https:// bmjopen.bmj.com/content/8/7/e020884

21. Voormolen DC, Polinder S, von Steinbuechel N, Vos PE, Cnossen MC, Haagsma JA. The association between post-concussion symptoms and healthrelated quality of life in patients with mild traumatic brain injury. Injury. 2019 May;50(5):1068-74.

22. Wäljas M, Iverson GL, Lange RT, Hakulinen U, Dastidar P, Huhtala $\mathrm{H}$, et al. A Prospective Biopsychosocial Study of the Persistent PostConcussion Symptoms following Mild Traumatic Brain Injury. Journal of Neurotrauma. 2014 Nov 3;32(8):534-47.

23. Ganti L, Conroy LM, Bodhit A, Daneshvar Y, Patel PS, Ayala S, et al. Understanding Why Patients Return to the Emergency Department after Mild Traumatic Brain Injury within 72 Hours. West J Emerg Med. 2015 May;16(3):481-5. 